\title{
Application of infrared remote sensing to constrain in-situ estimates of ice crystal particle size during SPartICus
}

\author{
S. J. Cooper and T. J. Garrett \\ Department of Atmospheric Science, University of Utah, Salt Lake City, UT 84112, USA
}

Received: 6 May 2011 - Published in Atmos. Meas. Tech. Discuss.: 23 May 2011

Revised: 15 August 2011 - Accepted: 16 August 2011 - Published: 18 August 2011

\begin{abstract}
In a prior paper (Cooper and Garrett, 2010), an infrared remote sensing technique was developed that quantifies the effective radius $r_{\mathrm{e}}$ of ice crystals in cirrus clouds. By accounting for a broad range of expected inversion uncertainties, this retrieval scheme isolates those radiometric signatures that can only occur if the cirrus has nominally "small" values of $r_{\mathrm{e}}$ below $20 \mu \mathrm{m}$. The method is applicable only for specific cloud and atmospheric conditions. However, it can be particularly useful in constraining in-situ estimates of cirrus cloud $r_{\mathrm{e}}$ obtained from aircraft. Recent studies suggest that airborne measurements may be compromised by the shattering of ice crystals on airborne instrument inlets, so robust, independent confirmation of these measurements is needed. Here, we expand the Cooper and Garrett (2010) retrieval scheme to identify ice clouds that are likely to have "large" values of $r_{\mathrm{e}}$ greater than $20 \mu \mathrm{m}$. Using MODIS observations, we then compare assessments of cirrus cloud $r_{\mathrm{e}}$ with in-situ measurements obtained during three test cases from the 2010 SPartICus campaign. In general, there is good agreement between retrievals and in-situ measurements for a "small" and "large" crystal case. For a more ambiguously "small" $r_{\mathrm{e}}$ case, the 2D-S cloud probe indicates values of $r_{\mathrm{e}}$ that are slightly larger than expected from infrared retrievals, possibly indicating a slight bias in the 2D-S results towards large particles. For our test cases, there is no evidence to suggest that an FSSP-100 with unmodified inlets produces measurements of $r_{\mathrm{e}}$ in cirrus that are strongly biased low.
\end{abstract}

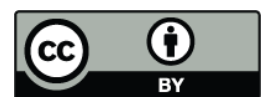

Correspondence to: S. J. Cooper (steve.cooper@utah.edu)

\section{Introduction}

There remains considerable dispute over the best method for characterizing in situ measurements of ice cloud particle size distributions (Garrett et al., 2005; McFarquhar et al., 2007; Jensen et al., 2009). This debate is centered about estimates of the effective radius $r_{\mathrm{e}}$, which is derived from in situ measurements of ice crystal size or from bulk measurements of the ice water content (IWC) and cloud extinction coefficient ( $\beta$ ) (Foot, 1988)

$r_{\mathrm{e}}=\frac{3 \mathrm{IWC}}{2 \rho \beta}$

where $\rho$ is the bulk ice density. The debate is not just quibbling over a few $\mu \mathrm{m}$ in ice crystal effective radius $r_{\mathrm{e}}$. Instead it is a robust discussion over whether and when cirrus ice particles are "small" rather than "large". In particular, there is a concern that in situ estimates of $r_{\mathrm{e}}$ are strongly biased low due to the possible shattering of ice crystals on the inlets of size distribution probes aboard fast-moving aircraft (Korolev and Isaac, 2005).

The recently completed Small Particles in Cirrus (SPartICus, January to June 2010) field campaign was designed in part to gain a more definitive estimate of cirrus particle size distributions. A primary objective of the the mission was to determine the extent to which ice crystal shattering affects in-situ cirrus measurements. A rigorous understanding of instrument dependent shattering processes would allow the development of a catalog of non-contaminated cirrus particle size distributions for use in remote sensing algorithms as well as insights into the validity of past in-situ cirrus measurements. Although comparison of in-situ results from different instrument and probe designs should provide some information on the prevalence of shattering, it would be useful to compare these in-situ results to remote sensing techniques for validation. With such an objective in mind, the

Published by Copernicus Publications on behalf of the European Geosciences Union. 
SPartICus program coordinated flights over the SGP ARM site and under-flew 21 overpasses of the NASA Afternoon A-Train constellation of satellites.

Satellite measurements would seem an ideal means to provide an independent check upon the in-situ measurements. Satellite measurements are non-invasive and are not complicated by potential shattering issues. Many approaches to estimate cloud properties from both active and passive remote measurements have been implemented over the past few decades (Inoue, 1985; Prabhakara et al., 1988; Nakajima and King, 1990; Austin and Stephens, 2001; Austin et al., 2009; Deng et al., 2010) for such programs as MODIS, ISCCP, CloudSat, and CALIPSO. Each of these retrieval schemes depends on known spectral sensitivities to invert measured radiances to estimates of $r_{\mathrm{e}}$. Unfortunately, each of these schemes also suffers from uncertainties due to assumptions used in the inversion process. Cooper et al. (2003, 2007), for instance, showed that required retrieval assumptions for ice crystal shape, ice particle size distribution, and cloud temperature can lead to uncertainties of order 30-40\% for passive MODIS based retrievals of ice crystal $r_{\mathrm{e}}$. For similar reasons, Deng et al. (2010) found that active retrievals of $r_{\mathrm{e}}$ from the CALIPSO lidar- CloudSat radar suite can have equally large uncertainties.

Given large uncertainties in both satellite retrievals and airborne measurements, we are in the curious situation of still having little that we can say confidently about the size distributions of cirrus ice crystals, even after seven decades of study (Weickmann, 1947). Naturally, this poses a problem for climate modeling: cirrus is often the first point where sunlight encounters atmospheric condensate, and last point of condensate thermal emission to space. Cirrus optical parameters are a primary constraint on the amount of energy that is available to the atmospheric system.

In light of such a fundamental uncertainty, in Cooper and Garrett (2010) we attempted to re-frame the ice cloud effective radius retrieval problem by describing a robust and simple passive infrared technique that could quantify cirrus ice crystal $r_{\mathrm{e}}$ with very low precision but with very high accuracy. Simply, the method identified cirrus clouds that had unambiguously "small" ice crystals with values of $r_{\mathrm{e}}$ less than about $20 \mu \mathrm{m}$. This retrieval scheme exploits the commonly known relationship between cloud $r_{\mathrm{e}}$ and the brightness temperature difference (BTD) between two spectral measurements within the atmospheric infrared window. Larger values of BTD generally indicate smaller values of $r_{\mathrm{e}}$. The Cooper and Garrett (2010) split-window application differs from previous applications of this method because it explicitly accounts for the effects on retrieval accuracy of assumptions for ice crystal habit, shape of the particle size distribution, and atmospheric temperature and humidity profiles. By careful consideration of sensitivities and uncertainties, it is possible to identify radiometric signatures that can only occur with the predominance of small particles less than about $20 \mu \mathrm{m}$.
The philosophy of this approach differs from that used, for example, in the commonly used MODIS operational $r_{\mathrm{e}}$ product (King et al., 1998). These schemes require an a priori "best guess" of the cloud microphysical, atmospheric, and surface properties. Since these schemes cannot know these quantities with certainty, they will provide inaccurate results when specific retrieval assumptions fail to match reality. By contrast, the Cooper and Garrett (2010) retrieval scheme is designed to be highly conservative, in that it is aimed at the confident identification of clouds with "small" values of ice crystals regardless of the range of expected uncertainties for these inversion assumptions. It can not be applied to all cirrus cloud cases, nor can it yield a highly specific estimate of $r_{\mathrm{e}}$ other than "small". However, it can be particularly useful in providing an independent constraint on in-situ airborne measurements. For applicable cases, it can determine whether in situ measurements of small particles are representative of nature, or are instead the likely result of ice crystal shattering on probe inlets.

The ubiquitous nature of the split-window measurements on satellite platforms allows for broad applicability of the technique to many field and satellite campaigns. In this paper, the Cooper and Garrett (2010) scheme is directly applied to observations from the SPartICus field campaign. This application illustrates how the technique can be applied while providing insight into the accuracy of various in-situ observations during the campaign. However, given the limited number of good test cases for our technique during the campaign, and the fact that our infrared technique was not considered for design of the campaign, we cannot present a broad characterization of SPartICus cloud properties or a definitive analysis of in situ instrument performance. The outline of this paper is as follows. Section 2 of this paper briefly reviews the general theoretical basis for selecting those radiometric signatures confidently associated with the presence of ice clouds composed of small particles. Although the Cooper and Garrett (2010) paper is designed only to identify small particles, it is shown here how the technique can be used to identify likely large particle cirrus cases given ideal observational constraints found during the field campaign. Section 3 applies the technique to in-situ and satellite observations during the SPartICus campaign. Sections 4 and 5 discuss and conclude, respectively.

\section{Retrieval technique}

L'Ecuyer et al. (2006) and Cooper et al. (2006) attempted to determine an ideal cloud retrieval method and associated uncertainties through a formal information content analysis (Shannon and Weaver, 1949; Rodgers, 2000). These studies quantified both radiance sensitivities and inversion uncertainties due to assumptions such as ice crystal habit, cloud temperature, cloud particle size distribution, and the atmospheric temperature and humidity profile, to determine those 
spectral measurements that contained the most information for cloud retrievals. These studies suggested that the infrared, split-window method (Inoue, 1985; Prabhakara et al., 1988) had the highest signal to noise ratio for the retrieval of cloud properties for thin cirrus. The more commonly used combined visible, near-infrared method (Nakajima and King, 1990) used in such programs as the MODIS operational effective radius product was found to be un-reliable for the retrieval of thin cirrus effective radius due to uncertainties in both microphysics and surface reflectance assumptions.

Given these findings, Cooper and Garrett (2010) developed an infrared technique using the $11.0 \mu \mathrm{m}$ and $12.0 \mu \mathrm{m}$ split-window channels to unambiguously identify "small" particles with values of $r_{\mathrm{e}}$ below $20 \mu \mathrm{m}$. The basic idea of this BTD technique was to choose a sufficiently high BTD threshold value that must be associated with small particles regardless of potential uncertainties in inversion assumptions. The logic of the BTD technique is reviewed in the following paragraphs. Readers desiring a more in-depth explanation of the uncertainty analysis used to develop this method should refer to Cooper and Garrett (2010) for details.

A thin cirrus cloud composed of small ice cloud particles will absorb more radiation near $12.0 \mu \mathrm{m}$ than near $11.0 \mu \mathrm{m}$. Provided the cloud does not radiate as a blackbody, a satellite sensor will observe a greater brightness temperature at $11.0 \mu \mathrm{m}$ than at $12.0 \mu \mathrm{m}$ wavelength. Since the ratio of absorption between these wavelengths (and thus the BTD between the two wavelengths) is a function of particle size, the resulting BTD can be used to infer the value of the cirrus cloud $r_{\mathrm{e}}$. This technique loses sensitivity for clouds that are very transparent or radiate as blackbodies, or as $r_{\mathrm{e}}$ approaches $30 \mu \mathrm{m}$. In any of these cases, the magnitude of absorption at $11.0 \mu \mathrm{m}$ and $12.0 \mu \mathrm{m}$ wavelength converges and sensitivity to precise particle size is lost.

Figure 1 illustrates forward radiative transfer calculations in the split-window arches format for a cloud temperature of $210 \mathrm{~K}$, a tropical atmosphere, and MODIS bandwidths. Cloud optical depth and effective radius pairs can be identified from the $11.0 \mu \mathrm{m}$ brightness temperature, and the $11.0 \mu \mathrm{m}$ minus $12.0 \mu \mathrm{m}$ BTD. Curves are shown for three different effective radii $(8,20$, and $48 \mu \mathrm{m})$, each for six different ice crystal habit assumptions (randomized aggregates, smooth aggregates, rough aggregates, solid hexagonal columns, bullets, and spheres), assuming a modified gamma distribution size distribution with variance parameter equal to two.

Figure 1 shows that, for a given ice crystal effective radius, different assumptions about the ice crystal habit produce curves with slightly different values of BTD (or the height of the arches), due to the difference in absorption characteristics at $11.0 \mu \mathrm{m}$ to $12.0 \mu \mathrm{m}$ wavelength. For example, for an effective radius of $8 \mu \mathrm{m}$, and given an observed $11.0 \mu \mathrm{m}$ brightness temperature between $250 \mathrm{~K}$ to $260 \mathrm{~K}$, values of BTD range between $6.5 \mathrm{~K}$ and $9.0 \mathrm{~K}$. For an effective radius of $48 \mu \mathrm{m}$, corresponding brightness temperature differences range between $-0.5 \mathrm{~K}$ and $2.0 \mathrm{~K}$.

While there is substantial spread in BTD depending upon the assumed particle habit, Fig. 1 suggests that it should be possible to choose a sufficiently high BTD threshold that is unambiguously associated with small values of cloud ice crystal effective radius. When $r_{\mathrm{e}}$ is small, to first order it is particle $r_{\mathrm{e}}$ that drives the magnitude of the BTD curves. For example, for a very cold ice cloud of $210 \mathrm{~K}$, BTD values greater than $4.0 \mathrm{~K}$ correspond with an ice cloud effective radius smaller than $20 \mu \mathrm{m}$, independent of ice crystal habit. Cooper and Garrett (2010) also examined the effects of cloud particle size distribution, surface emissivity, and misclassification of cloud scene on the selection of BTD threshold to identify small particles. Each of these factors were found to have a secondary effect on the BTD magnitude for thin cirrus clouds with optical depths between about 0.5 and 3.0. Such analysis suggested that a MODIS BTD value of $4 \mathrm{~K}$ was safely indicative of unambiguously "small" values of $r_{\mathrm{e}}$.

An important caveat to application of this method is that corresponding clear-sky BTD values (as dictated by local atmospheric temperature and moisture profiles) should be low compared to any BTD threshold assumption. Values less than $2.0 \mathrm{~K}$ are ideal. Practically, this is achieved through examination of the clear-sky pixels near the cloud of interest or by modeling satellite clear-sky brightness temperatures from nearby atmospheric sounding data.

In Cooper and Garrett (2010), the main goal was to develop a tool that could be used to confidently identify thin ice clouds with values of $r_{\mathrm{e}}$ that are smaller than $20 \mu \mathrm{m}$. The scheme was not designed to confidently identify "large" or "non-small" values of $r_{\mathrm{e}}$ larger than $20 \mu \mathrm{m}$. The reason for this constraint is evident from Fig. 1. A 6 K BTD is unambiguously associated with "small" ice crystals, regardless of any other assumptions. A 2 K BTD, on the other hand, could be associated with either "small" or "large" ice crystals, depending on a range of plausible conditions for cloud optical depth and clear-sky BTD.

That said, the SPartICus field campaign provided sufficient additional information on environmental conditions (insitu cloud temperature, approximate cloud optical depth, single layer cirrus, etc.) to make it possible to confidently determine whether or not values of ice cloud $r_{\mathrm{e}}$ were in fact "large" for some test cases. For instance, based on the arches shown in Fig. 1, an observed 1.5 K BTD for a thin cirrus cloud could only be associated with values of $r_{\mathrm{e}}$ greater than $20 \mu \mathrm{m}$. Again, many radiometric signatures will be ambiguous even with a well defined atmosphere. Still, a limited number of radiometric signatures should provide sufficiently unambiguous constraints to provide an independent check on the contribution of ice crystal shattering to the contamination of airborne in-situ measurements. 


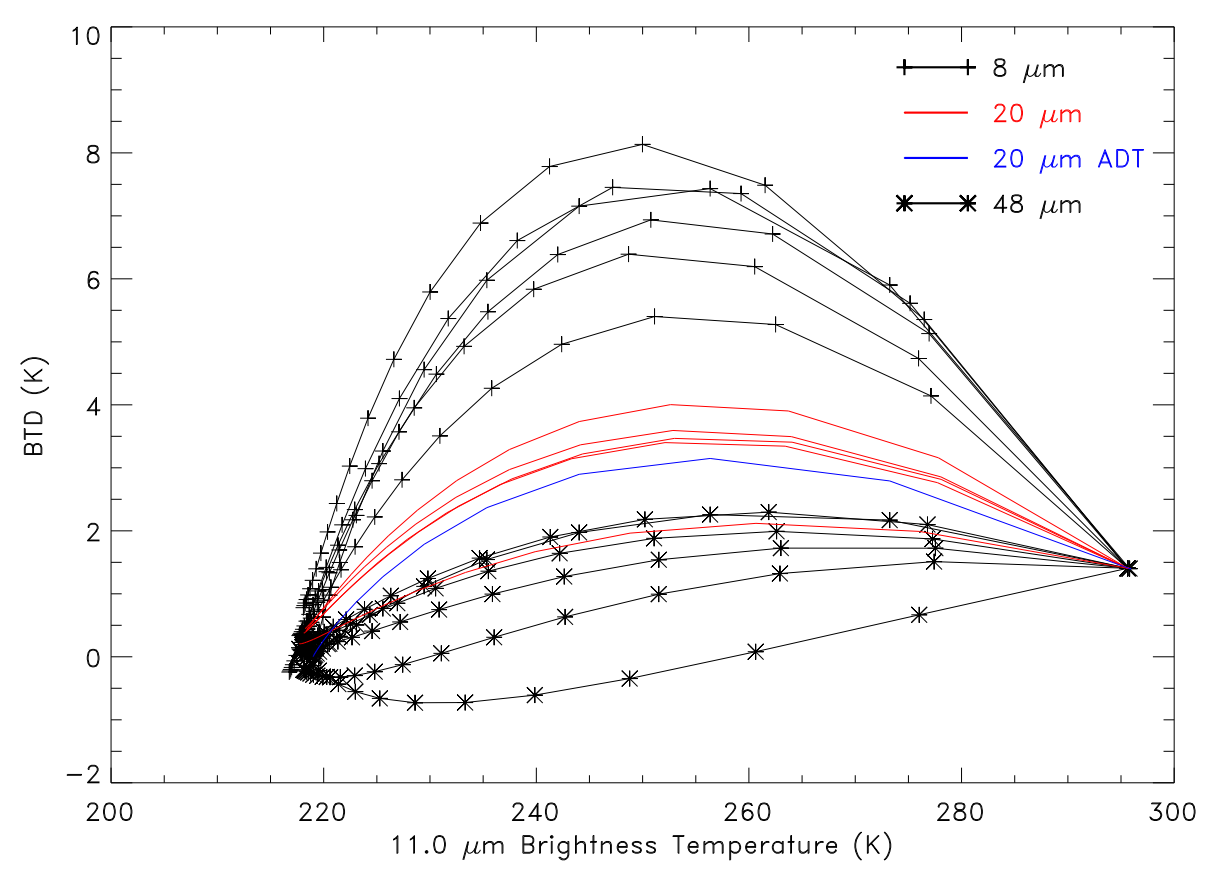

Fig. 1. Theoretical split-window arches for ice clouds composed of six different ice crystal habits (randomized aggregates, smooth aggregates, rough aggregates, solid hexagonal columns, and bullets (Yang et al., 2000) and spheres assuming anomalous diffraction theory) with a cloud temperature of $210 \mathrm{~K}$. Calculations are shown for three different effective radius $(8 \mu \mathrm{m}, 20 \mu \mathrm{m}$, and $48 \mu \mathrm{m})$ for each ice crystal type. Each symbol along a given line represents an increment of 0.5 in cloud optical depth, ranging from 0 at the right arch base to 10 at the left arch base.

\section{Application to SPartICus}

The Cooper and Garrett (2010) method can be broadly applied to any field campaign where BTD measurements are available. Here, we use it examine in situ measurements obtained during the Small Particles in Cirrus (SPartICus, 2010) field campaign.

The SPartICus field campaign consisted of approximately 200 flight hours with the SPEC 25 Learjet, which included for measurement of ice cloud particle size distributions the Cloud Droplet Probe (CDP, Lance et al., 2010), a fast Forward Scattering Spectrometer Probe (FSSP-100, Baumgardner et al., 1990), and a two-D stereo probe (2D-S, Lawson et al., 2006). To meaningfully compare co-incident measurements, it is necessary to understand the sensitivities and design of each of these instruments. The CDP and FSSP100 both use forward scattered light to estimate concentrations of "small" cloud particles with sizes roughly from 2 to $50 \mu \mathrm{m}$ diameter. The $2 \mathrm{D}-\mathrm{S}$ probe uses laser beams to create two dimensional silhouettes of particles with maximum dimensions exceeding $10 \mu \mathrm{m}$, and can see both "small" and "large" particles. The CDP has no shroud or inlet and therefore should not be susceptible to particle shattering concerns. The FSSP-100 and 2D-S design types, however, have previously been demonstrated to potentially cause shattering artifacts (Korolev and Isaac, 2005; Korolev et al., 2011).
In this section, the infrared BTD threshold technique is used to constrain estimates of particle size from these SPartICus in-situ measurements. Although the BTD technique can only determine if particles are "small" or "large" given specific radiometric signatures, such information should be useful to determine if the in-situ estimates of particle size are being strongly influenced by shattering. SPartICus was centered over the western US, allowing several underpasses of the Aqua MODIS instrument and the NASA Afternoon A-Train constellation of satellites. The idea here is to use the MODIS instrument aboard Aqua to identify cases where the SPEC 25 Learjet was located in large, relatively homogeneous areas of cloud with distinct "small" or "large" BTD signatures. Homogeneous cloud conditions should limit concerns about matching in-situ measurements to a given cloud pixel seen by MODIS.

For these analyses, MODIS based BTD estimates of $r_{\mathrm{e}}$ are compared to in-situ estimates provided by SPEC inc., which operated the in-flight instrumentation during the SPartICus campaign. Effective radius values are derived from the airborne direct measurements of size or projected area distributions, which are converted to estimates of the extinction coefficient $\beta$ and ice water content (IWC) using image to mass relationships described in Baker et al. (2006). The effective radius $r_{\mathrm{e}}$ is subsequently calculated using Eq. (1). 
SPEC Inc. supplied to the SPartICus archive 2D-S estimates of cloud properties, both with and without correction for possible shattering effects (see Lawson, 2011). Supplied FSSP-100 data was not corrected for possible shattering effects. Given that the FSSP-100 has sensitivity to small particles only, these measurements were combined with the observed large particles from the 2D-S instrument, thus allowing an estimate of the effective radius for the complete ice particle size distribution. Specifically, FSSP particles less than $50 \mu \mathrm{m}$ in maximum dimension were combined with 2D-S particles greater than $50 \mu \mathrm{m}$ through use of Eq. (1). Significant discrepancies between reported 2D-S concentrations and the combined FSSP+2D-S approaches may provide some insight into the degree that FSSP or 2D-S data have been contaminated by shattering artifacts.

Due to the cautious nature of the BTD retrieval scheme, the relatively small number of Aqua overpasses, and the necessity of having the plane located reasonably near to an acceptable BTD cloud field, we found only a handful of good test cases for comparing MODIS and airborne measurements during the SPartICus campaign. However, we present in the following paragraphs a clear "small" crystal case, a clear "large" crystal case, and a somewhat ambiguous "small" crystal case.

\subsection{A "small" case}

Case 1 represents a "small" crystal case that occurred on 28 April co-incident with the 1925 GMT MODIS Aqua overpass. Figure 2 shows $11.0 \mu \mathrm{m}$ brightness temperatures and the $11.0 \mu \mathrm{m}$ minus $12.0 \mu \mathrm{m}$ BTD fields from the overpass, indicating a large area of thin cirrus stretching from Texas to Kansas. The SPEC 25 Learjet was located in north central Oklahoma at the edge of the cirrus shield and a region of either clear-sky or extremely tenuous cirrus. Observed cloud brightness temperatures of $250 \mathrm{~K}$ to $260 \mathrm{~K}$ relative to warm surface temperatures $(290 \mathrm{~K})$ and cold cloud temperatures (near $220 \mathrm{~K}$ ) suggest that the cirrus has moderate optical depths that are ideal for application of the BTD retrieval scheme. As suggested by Fig. 1, such a combination of environmental conditions allows for elevated values of BTD to be observed provided that values of ice particle $r_{\mathrm{e}}$ are "small".

Values of BTD in the thin cirrus shield reach a maximum of $7 \mathrm{~K}$, but there are slightly lower values of $4 \mathrm{~K}$ to $5 \mathrm{~K}$ closer to the aircraft location. Clear-sky values of BTD located near the plane location were between $1 \mathrm{~K}$ and $1.5 \mathrm{~K}$, which is well below the $2 \mathrm{~K}$ "ideal" threshold we identified as being an a priori criterion for confidently applying the BTD identification method for ice crystal size. Thus, this is a clear case where ice crystal effective radii were unambiguously small around the aircraft location. It could be argued that vertical variability in $r_{\mathrm{e}}$ adds another degree of freedom that must be considered for co-location (Zhang et al., 2010). This is partly true. However, we assume the importance of vertical variability is small because the BTD scheme only applies
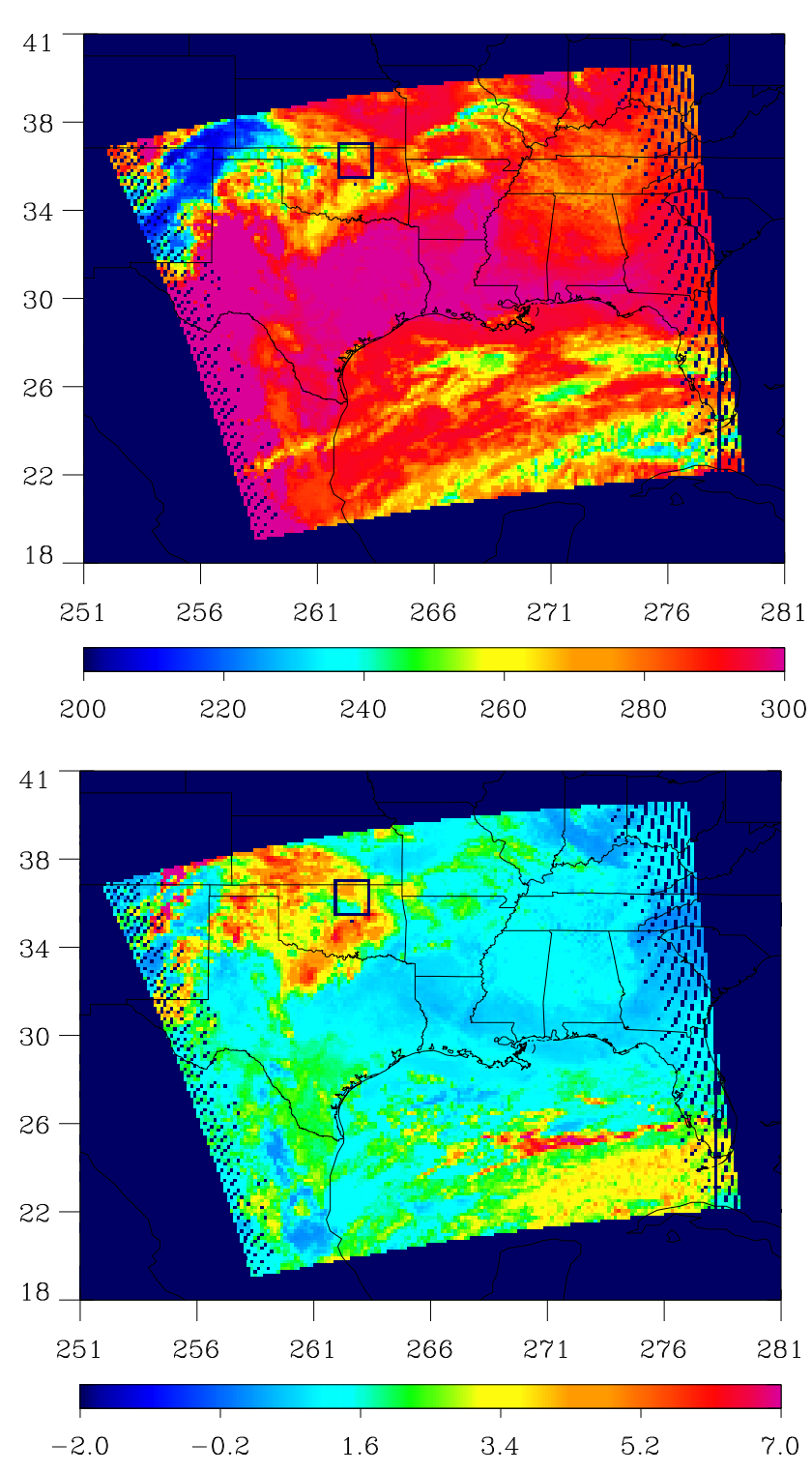

Fig. 2. Figure shows the MODIS $11.0 \mu \mathrm{m}$ brightness temperature (top panel) and the $11.0 \mu \mathrm{m}$ minus $12.0 \mu \mathrm{m}$ BTD (bottom panel) for the 28 April 1925 GMT overpass. The SPEC 25 Learjet was located in thin cirrus in north central Oklahoma as shown by the high BTD areas within the black box in the bottom panel. High values of BTD for these cirrus indicate clouds dominated radiatively by small crystals. The low BTD areas in the lower-left portion of the black box and corresponding high $11.0 \mu \mathrm{m}$ brightness temperatures indicate regions of clear-sky or very thin cirrus clouds.

to thermally transparent cirrus, where the entire cloud depth contributes to the measured radiative signature.

Both the 2D-S and FSSP probes were in operation at the time of the 28 April 1925 GMT MODIS overpass. Although the SPEC Learjet 25 was in extremely thin or perhaps even no cirrus at the exact time of the overpass, both instruments measured high concentrations of ice particles in the minutes 
that both immediately preceded and followed. For the flight leg from $10 \mathrm{~min}$ before the overpass until $10 \mathrm{~min}$ after the overpass, the 2D-S and FSSP probe provide average estimates of $r_{\mathrm{e}}$ of $17.0 \mu \mathrm{m}$ and $9.8 \mu \mathrm{m}$, respectively, for those times when both instruments had sensitivity to cloud particles. The combined FSSP and 2D-S and FSSP approach yielded an $r_{\mathrm{e}}$ of $16.1 \mu \mathrm{m}$. Such small values of $r_{\mathrm{e}}$ are consistent with the high coincident values of BTD detected by MODIS (Fig. 2). The precise values detected by the in situ probes do depend somewhat on the exact averaging period that is employed. Nonetheless, no reasonable shift in averaging time changes the conclusion that both the remote and in-situ measurements of ice crystal $r_{\mathrm{e}}$ concur that the particles are generally "small".

\subsection{A "large" case}

Case 2 represents a "large" crystal case that occurred on 17 March where the SPEC 25 Learjet was co-incident with the 2030 GMT MODIS Aqua overpass. The SPEC 25 Learjet was located in western Colorado in the middle of thin cirrus, as indicated by the MODIS infrared observations (Fig. 3). Observed cloud brightness temperatures of near $260 \mathrm{~K}$ relative to warm surface temperatures of $285 \mathrm{~K}$, and cold cloud temperatures near $228 \mathrm{~K}$ (as determined by in-situ observations), suggest moderate cloud optical depths necessary for application of the BTD retrieval scheme. Nearby clear-sky values of BTD are extremely low, and are near $1 \mathrm{~K}$ for the entire MODIS granule. For cirrus within $0.2^{\circ}$ latitude and longitude of the aircraft, the BTD averaged $1.6 \mathrm{~K}$, suggesting ice crystals with "large" values of $r_{\mathrm{e}}$ dominate the cloud sampled by the aircraft in this case.

For comparison, both the 2D-S and FSSP probes aboard the SPEC Learjet 25 indicated the presence of thin cirrus with relatively uniform values of $\beta$ and IWC. Averaged over a flight leg from $5 \mathrm{~min}$ before the overpass until $5 \mathrm{~min}$ after the overpass, the 2D-S and FSSP probes found averaged values of $r_{\mathrm{e}}$ of $37.7 \mu \mathrm{m}$ and $25.3 \mu \mathrm{m}$, respectively. The combined FSSP and 2D-S approach yielded an $r_{\mathrm{e}}$ of $36.8 \mu \mathrm{m}$. The "large" values of $r_{\mathrm{e}}$ that are measured in situ are consistent with those that are inferred from the low values of BTD observed by Aqua MODIS (Fig. 3). Reasonable changes to the averaging time do not alter the implied consistency.

\subsection{An intermediate case}

Case 3 comes from 7 June, co-incident with the 2015 GMT MODIS Aqua overpass, where there is less conclusive agreement between the in situ measurements and the BTD scheme for assessing particle size. The SPEC 25 Learjet was located in central Colorado along the Front Range in the midst of a large cloud system covering much of the western US. BTD values shown in Fig. 4 ranged between $5 \mathrm{~K}$ and $7 \mathrm{~K}$ for large areas of the observed cirrus. However, they averaged only $4.1 \mathrm{~K}$ for MODIS pixels within a few tenths of a degree lat-
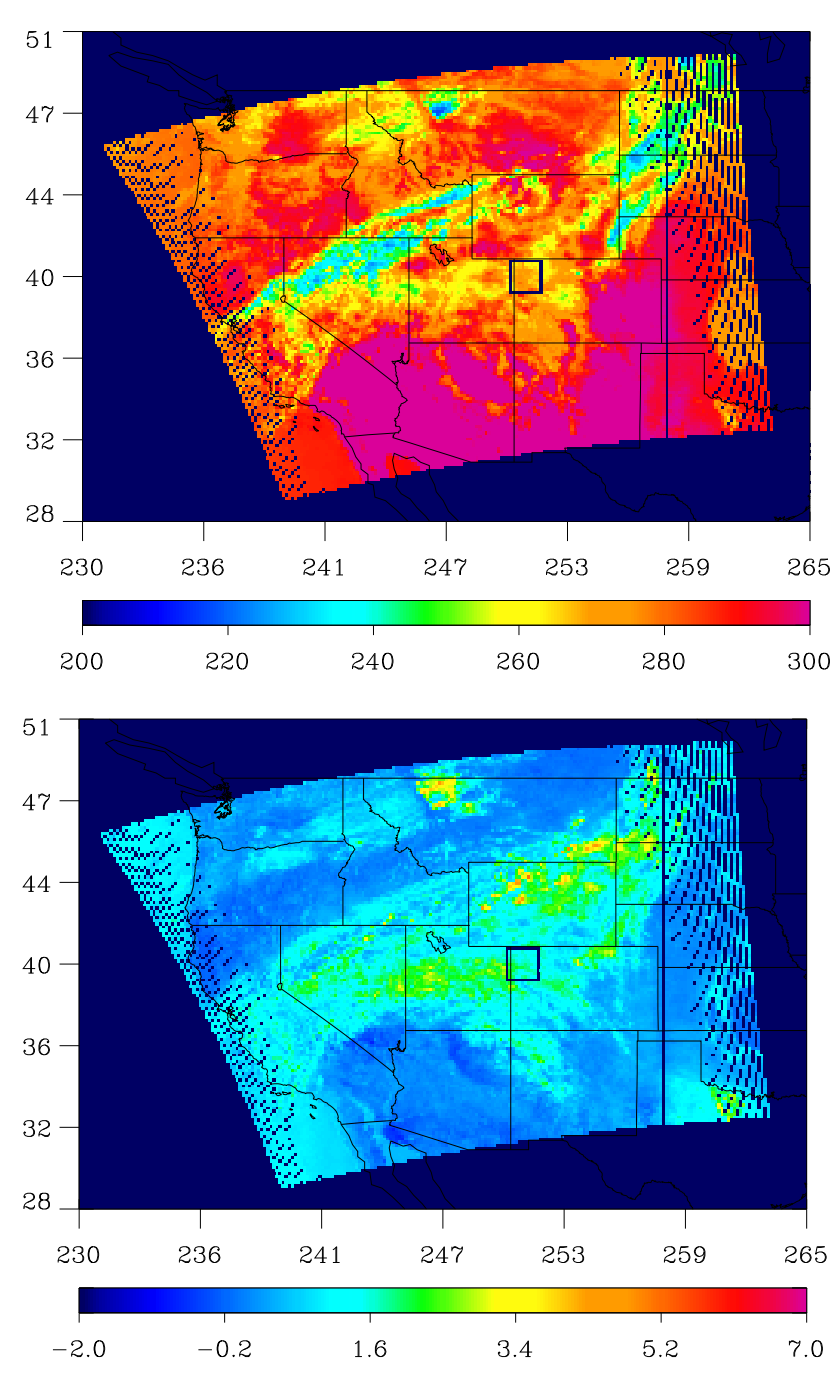

Fig. 3. Figure shows the MODIS $11.0 \mu \mathrm{m}$ brightness temperature (top panel) and the $11.0 \mu \mathrm{m}$ minus $12.0 \mu \mathrm{m}$ BTD (bottom panel) for the 17 March 2030 GMT overpass. The SPEC 25 Learjet was located in thin cirrus in western Colorado as indicated by the low BTD areas in the black box. Low values of BTD for these cirrus suggest clouds dominated by large crystals for this case.

itude and longitude of the concurrent aircraft position. The combination of warm surface temperature (near $300 \mathrm{~K}$ ), cold cloud temperatures $(220 \mathrm{~K}$ as indicated by in-situ measurements), observed brightness temperatures (near $270 \mathrm{~K}$ ), and clear-sky BTD values no greater than $2 \mathrm{~K}$ indicate clouds of moderate optical depth and good applicability for the BTD threshold technique as discussed in Sect. 2. Thus, the generally high values of BTD that were observed around the aircraft position suggest that values of $r_{\mathrm{e}}$ in this cirrus were "small".

Coincident 2D-S and CDP measurements (FSSP data not available) averaged over a period of $10 \mathrm{~min}$ about the 2015 GMT MODIS overpass time indicate average values of $r_{\mathrm{e}}$ of $23.6 \mu \mathrm{m}$ and $15.1 \mu \mathrm{m}$, respectively. The combined CDP 
and 2D-S approach using Eq. (1) indicates $r_{\mathrm{e}}$ values of $17.0 \mu \mathrm{m}$. Thus, the 2D-S measurements suggest values of $r_{\mathrm{e}}$ that slightly exceed the $20 \mu \mathrm{m}$ threshold identified using the BTD approach. Nonetheless, the difference is not excessive given that the observed BTD values only marginally exceed the nominal 4K BTD "small" cutoff. Further the combined 2D-S and CDP measurements are in fact consistent with the BTD approach. Also, it should be noted that over 30 percent of the individual 2D-S measurements obtained over the averaging time period did in fact have values of $r_{\mathrm{e}}$ that were below $20 \mu \mathrm{m}$. Regardless of exact numbers, both in-situ observations and inferences from MODIS BTD observations suggest the significant presence of small ice particles.

\section{Discussion}

Table 1 summarizes the BTD and airborne estimates of the values of $r_{\mathrm{e}}$ for these three SPartICus ice cloud cases (Table 2 summarizes average IWC and extinction values for the various test scenarios presented in this paper). Taken as a whole, there is a general consistency between the values of $r_{\mathrm{e}}$ obtained from in situ measurements and the coarse resolution size classification provided by the MODIS BTD scheme. There is only one possible exception, which is for Case 3, where the 2D-S measurements found values of $r_{\mathrm{e}}$ that marginally exceeded the $20 \mu \mathrm{m}$ "small" threshold, even when the BTD scheme indicated the cirrus was indeed characterized by "small" effective radii. Consistency was achieved only if the CDP was included in the calculations of $r_{\mathrm{e}}$. The veracity of the $\mathrm{CDP}$, however, is not beyond question as results from several flight legs not presented in this paper included measurements of $r_{\mathrm{e}}$ that were below $4 \mu \mathrm{m}$, which perhaps is overly small. Regardless, differences between 2D-S observations and expectations from the BTD scheme might suggest that some fraction of total optical extinction was excluded from measurement by the 2D-S, either due to an erroneous application of the SPEC Inc. shattering algorithm, or that the 2D-S is insufficiently sensitive to very small particles to begin with (Lawson, 2011; Baumgardner, 2011). Alternatively, as discussed above, the case is insufficiently conclusive to make a firm assessment of instrument performance either way.

Since the FSSP-100 lacks sensitivity to "large" particles, the FSSP-100 measured effective radius values presented in Table 1 do not describe the complete size distribution. No robust comparison can be made between FSSP-100 values of $r_{\mathrm{e}}$ and those inferred from the infrared BTD scheme. However, the overall response of the FSSP-100 is consistent with what is expected, even if the data are ostensibly subject to ice crystal shattering. Appropriately, the measurements indicate "small" effective radii $(9.8 \mu \mathrm{m})$ for the small crystal case and "large" radii $(25.3 \mu \mathrm{m})$ for the large crystal case. Perhaps more interesting, comparisons of results between the 2D-S probe and the combined 2D-S plus FSSP scheme indicate
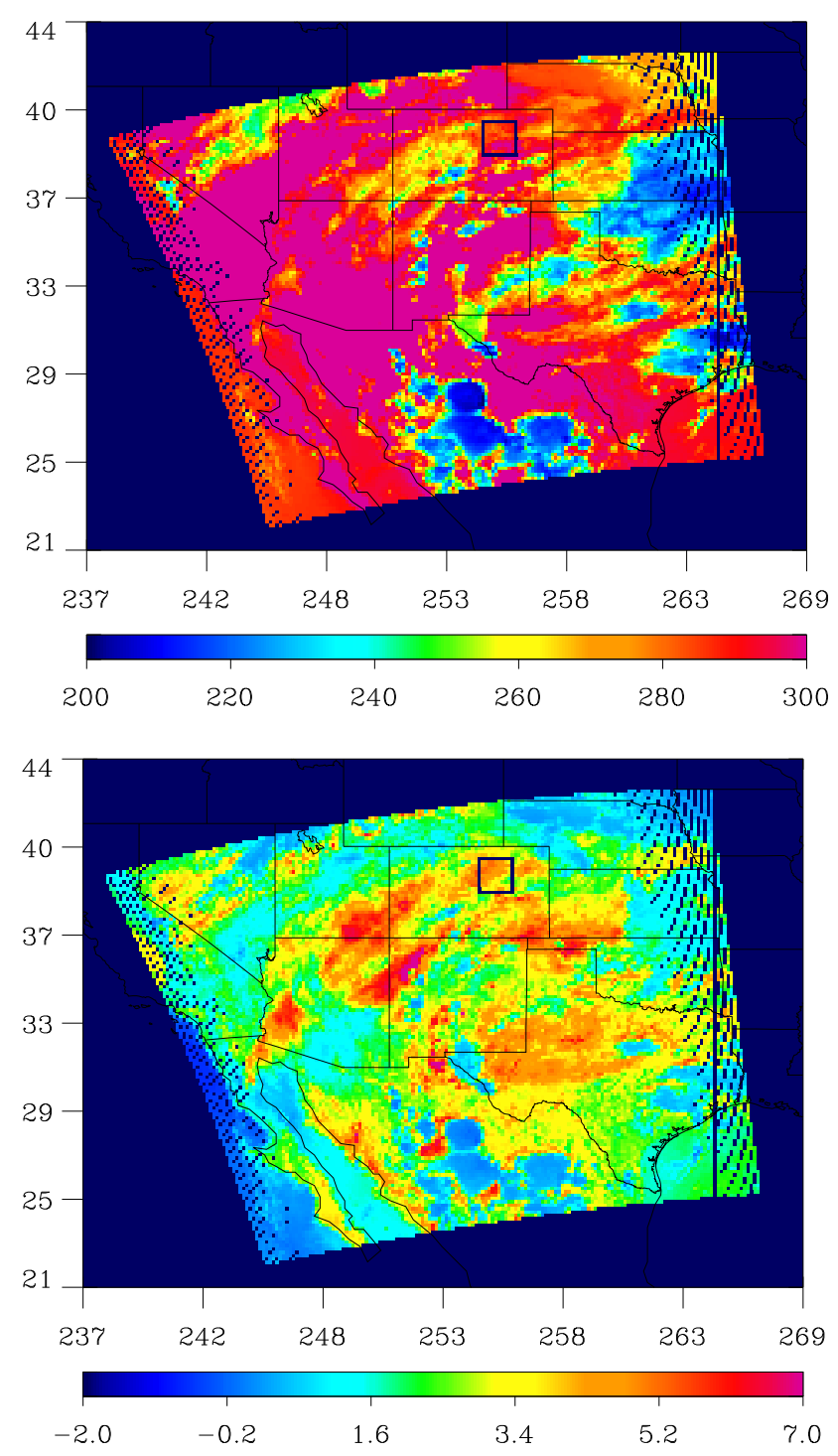

Fig. 4. Figure shows the MODIS $11.0 \mu \mathrm{m}$ brightness temperature (top panel) and the $11.0 \mu \mathrm{m}$ minus $12.0 \mu \mathrm{m}$ BTD (bottom panel) for the 7 June 2015 GMT overpass. The SPEC 25 Learjet was located in thin cirrus along the Front Range of Colorado as shown by the high BTD areas within the black box in the bottom panel. High values of BTD for the cirrus suggest clouds dominated radiatively by small crystals. The low BTD areas in the lower-right portion of the black box and corresponding high $11.0 \mu \mathrm{m}$ brightness temperatures indicate regions of clear-sky or very thin cirrus clouds.

very similar values of $r_{\mathrm{e}}$ for both the large and small crystal cases. Such consistency among probes and with the BTD schemes imply that the FSSP-100 results have not been contaminated by excessive shattering.

Korolev and Isaac (2005), however, have demonstrated that ice crystals can shatter on airborne instrument inlets to produce a shower of smaller crystals that will artificially exaggerate the measured value of $\beta$. Such events will only 
Table 1. Estimated effective radius in $\mu \mathrm{m}$ from SPEC 25 Learjet in-situ instrumentation and infrared BTD threshold scheme for three MODIS overpass test cases observed during SPartICus.

\begin{tabular}{llrcrrrr}
\hline Case & Date & Observed BTD & BTD Scheme & 2D-S & FSSP & CDP & Combined \\
\hline 1 & 28 April & $4-5 \mathrm{~K}$ & $<20$ & 17.0 & 9.8 & NA & 16.1 \\
2 & 17 March & $2 \mathrm{~K}$ & $>20$ & 37.7 & 25.3 & NA & 36.8 \\
3 & 7 June & $4 \mathrm{~K}$ & $<20$ & 23.6 & NA & 15.1 & 17.0 \\
\hline
\end{tabular}

Table 2. Table shows in-situ estimates of IWC and extinction coefficient $\beta$ from each 2D-S, FSSP, and CDP instruments for 17 March, 28 April, and 7 June thin cirrus test cases.

\begin{tabular}{lcrrr}
\hline Instrument & Case & Date & IWC $\left(\mathrm{g} \mathrm{m}^{-3}\right)$ & $\beta\left(\mathrm{km}^{-1}\right)$ \\
\hline 2D-S & 1 & 28 April & 0.00048 & 0.043 \\
FSSP & 1 & 28 April & 0.00055 & 0.035 \\
2D-S & 2 & 17 March & 0.0092 & 0.396 \\
FSSP & 2 & 17 March & 0.0021 & 0.11 \\
2D-S & 3 & 7 June & 0.011 & 0.698 \\
CDP & 3 & 7 June & 0.07 & 7.74 \\
\hline
\end{tabular}

change measured values of $r_{\mathrm{e}}$ if they are sufficiently catastrophic to significantly alter the bulk volume to area ratio of the measured particles. For the "large" $r_{\mathrm{e}}$ case examined above, Table 3 presents estimates of cloud IWC $\beta$, number concentration $N$ and $r_{\mathrm{e}}$ with possible shattering effects included, alongside those with the SPEC Inc. shattering removal algorithm applied (Lawson, 2011). The shattering removal algorithm results in some moderate reductions to the calculated values of IWC, extinction, and number concentration. However, they do not lead to any fundamental change in the relationship between IWC and $\beta$, meaning that there is only a minute change in the calculated value of effective radius. The calculated values of $r_{\mathrm{e}}$ are $37.6 \mu \mathrm{m}$ with shattering, versus $37.7 \mu \mathrm{m}$ when the shattering removal algorithm is applied.

Figure 5 shows the 2D-S measured ice particle size distributions both with and without application of the Spec Inc. shattering algorithm. Both curves suggest a bi-modal size distribution with the greatest number concentrations found for the smallest measured size bin near $10 \mu \mathrm{m}$. Given the 2D-S probe cannot measure particles less than $10 \mu \mathrm{m}$, it is highly likely that a significant number of particles less than $10 \mu \mathrm{m}$ exist. Since these smallest particles would not be considered in deriving 2D-S cloud properties, a possible bias towards large particles in the 2D-S results could occur. Such a scenario could explain the observed discrepancy in effective radius between the BTD scheme and the 2D-S measurements for Case 3.
Table 3. Table shows in-situ estimates of IWC, the extinction coefficient $\beta$, number concentration $N$, and effective radius $r_{\mathrm{e}}$ from the 2D-S probe for the 17 March large crystal case. Estimates without and with a shattering algorithm applied are shown in the left and right columns, respectively.

\begin{tabular}{lrr}
\hline & $\begin{array}{r}\text { Without } \\
\text { Shattering } \\
\text { Algorithm }\end{array}$ & $\begin{array}{r}\text { Shattering } \\
\text { Algorithm } \\
\text { Applied }\end{array}$ \\
\hline $\mathrm{IWC}\left(\mathrm{g} \mathrm{m}^{-3}\right)$ & 0.011 & 0.0092 \\
$\beta\left(\mathrm{km}^{-1}\right)$ & 0.478 & 0.396 \\
$N\left(\mathrm{~L}^{-1}\right)$ & 108 & 49 \\
$r_{\mathrm{e}}(\mu \mathrm{m})$ & 37.6 & 37.7 \\
\hline
\end{tabular}

\section{Conclusions}

In Cooper and Garrett (2010), we developed a technique for the remote identification of cases in thin cirrus where values of the ice crystal effective radius $r_{\mathrm{e}}$ were unambiguous "small", or less than $20 \mu \mathrm{m}$. The method was designed from information content considerations and it exploits a known sensitivity to ice cloud $r_{\mathrm{e}}$ of the infrared brightness temperature difference (BTD) between two bands in the atmospheric infrared window. Although the technique can only be applied to clouds of moderate optical depths, it is highly accurate, and can be used to confidently identify the presence of small values of $r_{\mathrm{e}}$ given only limited information on atmospheric and cloud conditions. By contrast, the more commonly implemented operational approach using a combination of visible and near-infrared measurements has sensitivity to a much greater range of cloud properties. However, it suffers from potential uncertainties in inversion assumptions such as ice crystal habit and surface albedo that can make retrieval results for thin clouds highly dubious. Here, the Cooper and Garrett (2010) approach is extended to identify, with somewhat less confidence, cases that are characterized by "non-small" or "large" particles with values of $r_{\mathrm{e}}$ that are greater than $20 \mu \mathrm{m}$, provided a few observational constraints. The particular utility of this BTD threshold technique is that, where applicable, it can provide an independent check on the validity of airborne in-situ measurements of $r_{\mathrm{e}}$. This is important because currently there is a great deal of ambi- 


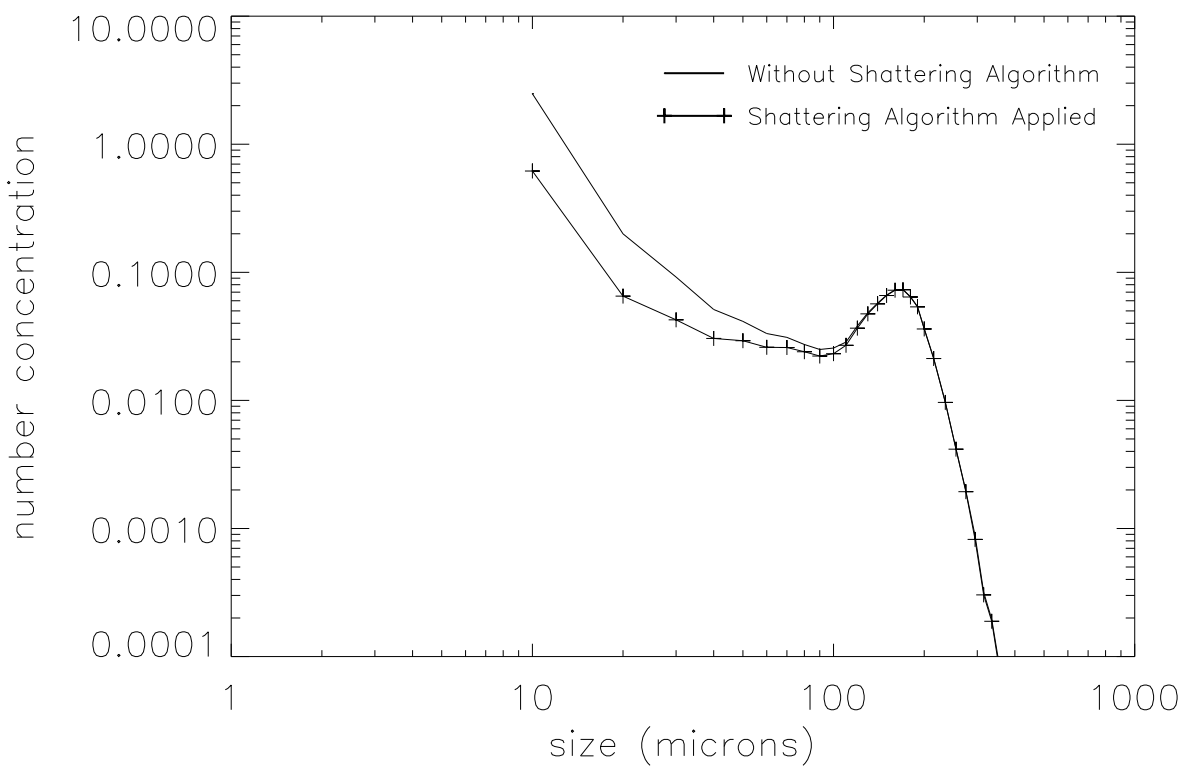

Fig. 5. Measured 2D-S ice particle size distributions both with and without application of a shattering algorithm (Lawson, 2011) used to correct for possible shattering effects for the 17 March large crystal case.

guity surrounding the validity of in situ measurements of $r_{\mathrm{e}}$ due to concerns that the measurements may be contaminated by shattering of ice crystals on airborne instrument inlets. Depending on whether the BTD threshold technique identifies thin cirrus as having values of $r_{\mathrm{e}}$ that are unambiguously "small" or "large", an assessment can be made of the likely extent to which shattering has biased in the situ measurements to erroneously small values.

Here, we have applied this approach to one recent field campaign, SPartICus. We found that, in general, all airborne instruments, including an FSSP-100 with unmodified inlets, show good agreement between in situ estimates of ice crystal $r_{\mathrm{e}}$ and the BTD threshold technique. The 2D-S instrument found small ice crystals for the obviously small ice crystal radiometric signature of 28 April and found large ice crystals for the obviously large ice crystal radiometric signature of 17 March. But for a slightly more ambiguous "small" case on 7 June, where BTD varied greatly but averaged $4 \mathrm{~K}$ near the plane location, the 2D-S average $r_{\mathrm{e}}$ was slightly above the $20 \mu \mathrm{m}$ "small" particle cut-off at $23 \mu \mathrm{m}$. It is possible that the 2D-S lower size threshold of $12.5 \mu \mathrm{m}$ means some significant fraction of total extinction is missed at smaller sizes.

The simplicity of approach described here, along with the fact that IR split-window measurements are commonplace on both satellite (e.g. MODIS and GOES) and high-resolution aircraft (e.g. MODIS Airborne Simulator) platforms, means that the method described here can be applied to any field campaign dedicated to the sampling of cirrus. It offers a useful means for constraining in-situ estimates of ice crystal $r_{\mathrm{e}}$ and the extent to which shattering effects may be contaminating the measurements. Ideally, our infrared technique would be applied in concert with an instrument with high temporal and spatial resolution such as the MODIS Airborne Simulator both to maximize the number of cases and to minimize sampling issues. These could be combined with airborne vertical profiles to better assess the impact of the vertical variability of effective radius on comparisons. Furthermore, the technique may also prove useful in comparison with $r_{\mathrm{e}}$ retrieval schemes based on co-incident measurements from Doppler lidar (Westbrook and Illingworth, 2009) or radar, or those based on MODIS radiances outside the atmospheric window.

Acknowledgements. We greatly appreciate the efforts of all those involved with SPartICus but give special thanks to Jay Mace, Chris Schwartz, Paul Lawson, and Qixu Mo. Funding was provided through NASA Research Grant NNX08AH58G and through the Environmental Science Division of the US Department of Energy (Grant DE-FG0398ER62571). Data were obtained from the Atmospheric Radiation Measurements Program sponsored by the US Department of Energy Office of Science, Office of Biological and Environmental Research, Environmental Science Division.

Edited by: A. Kokhanovsky

\section{References}

Austin, R. and Stephens, G.: Retrieval of stratus cloud microphysical parameters using millimeter-wave radar and visible optical depth in preparation for CloudSat, J. Geophys. Res., 106, 28233 28242, 2001.

Austin, R., Heymsfield, A., and Stephens, G.: Retrieval of ice cloud microphysical parameters using the CloudSat millimeter- 
wave radar and temperature, J. Geophys. Res., 114, D00A23, doi:10.1029/2008JD010049, 2009.

Baker, B., Lawson, R., and Baker, B.: Improvement in Determination of Ice Water Content from Two-Dimensional Particle Imagery. Part I: Image-to-Mass Relationships, J. Appl. Meteorol. Clim., 45, 1282-1290, 2006.

Baumgardner, D.: Interactive comment on: Effects of ice particle shattering on optical cloud particle probes by Paul Lawson, Atmos. Meas. Tech. Disc., 4, C236-C240, 2011.

Baumgardner, D., Cooper, W., and Dye, J.: Optical and electronic limitations of the forward-scattering spectrometer probe, in: Liquid Particle Size Techniques, Vol. 2 ASTM STP 1083, edited by: Hirleman, E., Bachalo, W., and Felton, P., 115-127, American Society for Testing and Materials, 1990.

Cooper, S. and Garrett, T.: Identification of small ice crystals using passive radiometric observations, J. Appl. Meteorol., 49, 23342347, 2010.

Cooper, S., L'Ecuyer, T., and Stephens, G.: The impact of explicit cloud boundary information on ice cloud microphysical property retrievals from infrared radiances, J. Geophys. Res., 108, 4107, doi:10.1029/2002JD002611, 2003.

Cooper, S., L'Ecuyer, T., Gabriel, P. K., Baran, A., and Stephens, G.: Objective assessment of the information content of visible and infrared radiance measurements for cloud microphysical property retrievals over the global oceans. Part 2: Ice clouds, J. Appl. Meteorol., 45, 42-62, 2006.

Cooper, S., L'Ecuyer, T., Gabriel, P. K., Baran, A., and Stephens, G.: Performance assessment of a five-channel estimation-based ice cloud retrieval scheme for use over the global oceans, J. Geophys. Res., 112, D04207, doi:10.1029/2006JD007122, 2007.

Deng, M., Mace, G., Zhein, Z., and Okamoto, H.: Tropical Composition, Cloud, and Climate Coupling Experiment validation for cirrus cloud profiling retrieval using CLoudSat radar and CALIPSO lidar, J. Geophys. Res., 115, D00J15, doi:10.1029/2009JD013104, 2010.

Foot, J.: Some observations of the optical properties of clouds. Part II: Cirrus, J. Quant. Spectrosc. Radiat. Transfer, 114, 145-164, 1988.

Garrett, T., Navarro, B., Twohy, C., Jensen, E., Baumgardner, D., Bui, P., Gerber, H., Herman, R., Heymsfield, A., Lawson, P., Minnis, P., Nguyen, L., Poellot, M., Pope, S. K., Valero, F., and Weinstock, E.: Evolution of a Florida Anvil Cirrus, J. Atmos. Sci, 62, 2352-2372, 2005.

Inoue, T.: On the temperature and effective emissivity determination of semi-transparent cirrus clouds by bi-spectral measurements in the $10 \mu \mathrm{m}$ window region, J. Meteorol. Soc. JPN, 63, 88-89, 1985.

Jensen, E. J., Lawson, P., Baker, B., Pilson, B., Mo, Q., Heymsfield, A. J., Bansemer, A., Bui, T. P., McGill, M., Hlavka, D., Heymsfield, G., Platnick, S., Arnold, G. T., and Tanelli, S.: On the importance of small ice crystals in tropical anvil cirrus, Atmos. Chem. Phys., 9, 5519-5537, doi:10.5194/acp-9-5519-2009, 2009.

King, M., Tsay, S.-C., Platnick, S., Wang, M., and Liou, K.: Cloud retrieval algorithms for MODIS: Optical thickness, effective particle radius, and thermodynamic phase, Algorithm Theor. Basis Doc. ATBDMOD-05, nASA Goddard Space Flight Cent., Greenbelt, Md., 1998.
Korolev, A. and Isaac, G.: Shattering during Sampling by OAPs and HVPS. Part I: Snow Particles, J. Atmos. Oceanic Technol., 22, 528-542, 2005.

Korolev, A., Emery, E., Strapp, J., Cober, S., Isaac, G., Wasey, M., and Marcott, D.: Small ice particles in tropospheric clouds: fact or artifact? Airborne Icing Instrumentation and Evaluation Experiment, B. Am. Meteorol. Soc., 91, doi:10.1175/2010BAMS3141.1, in press., 2011.

Lance, S., Brock, C. A., Rogers, D., and Gordon, J. A.: Water droplet calibration of the Cloud Droplet Probe (CDP) and inflight performance in liquid, ice and mixed-phase clouds during ARCPAC, Atmos. Meas. Tech., 3, 1683-1706, doi:10.5194/amt3-1683-2010, 2010

Lawson, R. P.: Effects of ice particles shattering on the 2D-S probe, Atmos. Meas. Tech., 4, 1361-1381, doi:10.5194/amt-4-13612011, 2011.

Lawson, R. P., O’Connor, D., Zmarzly, P., Weaver, K., Baker, B., and Mo, Q.: The 2D-S (Stereo) Probe: Design and Preliminary Tests of a New Airborne, High-Speed, High-Resolution Particle Imaging Probe, J. Atmos. Oceanic Technol., 23, 1462-1477, 2006.

L'Ecuyer, T., Gabriel, P., Leesman, K., Cooper, S., and Stephens, G.: Objective assessment of the information content of visible and infrared radiacne measurements for cloud microphysical property retrievals over the global oceans. Part 1: Liquid clouds, J. Appl. Meteorol., 45, 20-41, 2006.

McFarquhar, G., Um, J., Freer, M., Baumgardner, D., Kok, G., and Mace, G.: The importance of small ice crystals to cirrus properties: Observations from the Tropical Warm Pool International cloud Experiment (TWP-ICE), Geophys. Res. Lett., 57, L13803, doi:10.1029/2007GL029865, 2007.

Nakajima, T. and King, M.: Determination of the optical thickness and effective particle radius of clouds from reflected solar radiation measurements. Part I: Theory, J. Atmos. Sci, 47, 1878-1893, 1990.

Prabhakara, C., Fraser, R., Wu, M., and Curran, R.: Thin cirrus clouds: seasonal distributions over oceans deduced from NIMBUS-4 IRIS, J. Appl. Meteorol., 27, 379-399, 1988.

Rodgers, C.: Inverse Methods for Atmospheric Sounding, World Scientific Publishing, River Edge, NJ, 2000.

Shannon, C. and Weaver, W.: The mathematical theory of communication, University of Illinois Press, Urbana, IL, 1949.

Weickmann, H.: Die Eisphase in der Atmosphare, library Trans. 273, Royal Aircraft Establishment, 1947.

Westbrook, C. and Illingworth, A.: Testing the influence of small crystals on ice size spectra using Doppler lidar observations, Geophys. Res. Lett., 36, L12810, doi:10.1029/2009GL038186, 2009.

Yang, P., Liou, K., Wyser, K., and Mitchell, D.: Parameterization of the scattering and absorption properties of individual ice crystals, J. Geophys. Res., 105, 4699-4718, 2000.

Zhang, Z., Platnick, S., Yang, P., Heidinger, A., and Comstock, J.: Effects of ice particle size vertical inhomogeneity on the passive remote sensing of ice clouds, J. Geophys. Res., 115, D17203, doi:10.1029/2010JD013835, 2010. 